\title{
JH

\section{Predictive accuracy of blood inflammatory markers on COVID-19 mortality}

\author{
Visuddho Visuddho ${ }^{1}$, Agus Subagjo ${ }^{2}$, Retno Asih Setyoningrum ${ }^{3 *}$, Alfian Nur Rosyid ${ }^{4}$
}

\begin{abstract}
Background: The impact of COVID-19 may be more severe in developing countries. Our study aims to analyze the accuracy of several inflammatory biomarkers in predicting COVID-19 mortality, providing information about the most suitable markers for developing countries.

Methods: A retrospective cohort study was conducted at Dr. Soetomo General Hospital, Indonesia, from March to June 2020. White Blood Cells (WBC) count, Neutrophil-Lymphocyte Ratio (NLR), Procalcitonin (PCT), D-Dimer, and $\mathrm{C}$-Reactive Protein (CRP) have been collected from the electronic medical records. We performed survival analysis to provide the hazard ratio and Receiver Operating Characteristic (ROC) curve analysis to test for accuracy for each parameter.

Results: A total of 423 patients who met the criteria for participating had a median age of 54 (IQR 45-61) years. Patients in the death group are characterized by older age and shorter length of hospitalization. The WBC, NLR, PCT, $\mathrm{D}$-Dimer, and CRP are found significantly higher in the death group $(P=0.000)$. The WBC, NLR, PCT, D-Dimer, and CRP have an Area Under the Curve (AUC) of 0.709, 0.773, 0.738, 0.721, and 0.769, respectively moderate accuracy in predicting COVID-19 patient mortality. We found that NLR is significantly more accurate than the age parameter $(Z=3.527 ; P=0.000)$ but has equal accuracy with other laboratory parameters.
\end{abstract}

Conclusion: Since NLR obtained the highest accuracy, we still recommend routine complete blood count tests as prognostic biomarkers with the highest feasibility to be performed in developing countries.

Keywords: Covid-19, Infectious Disease, Laboratory, Inflammatory, Marker, Predictive, Indonesia

\section{Background}

Coronavirus Disease 2019 (COVID-19) has been one of the most significant global pandemics. Recently, on July 27th, 2021, Indonesia contributed the third-highest number of new COVID-19 cases in the world [1]. The exponential increase of COVID-19 patients is also found in Indonesia, with 3,532,567 cases and 100,636 deaths as of August 4th, 2021 [2]. Therefore, Indonesia, and other developing countries, must increase awareness and develop the most well-suited guidelines for COVID-19 management. The early identification can provide necessary information for managing COVID-19 patients [3,4]. A previous study showed an association between several biomarkers to the severity and mortality of COVID-19 patients [5-7]. Early laboratory examinations are necessary to predict worsened outcomes and prepare the most advisable management for patients [5,8]. However, few studies from a large developing country like Indonesia reported early

*Correspondence: retno-a-s@ fk.unair.ac.id

$3^{3 *}$ Department of Pediatrics, Faculty of Medicine, Universitas Airlangga Jl.

Mayjen Prof. Dr. Moestopo 47, Surabaya, East Java 60132, Indonesia. laboratory examination on predicting survival and mortality. The white blood cell count (WBC) and neutrophil-lymphocyte ratio (NLR) have been recognized as routine hematological markers that have been used widely in clinical settings $[9,10]$. The WBC and NLR have good predictive accuracy in predicting poor clinical outcomes $[11,12]$. However, previous studies show that only the newer inflammatory biomarker, procalcitonin (PCT), has high accuracy in predicting COVID-19 poor outcomes in critical conditions [13]. The findings were also supported by one meta-analysis, showing the accuracy of PCT was $90.5 \%$, while other markers (WBC, NLR, and CReactive Protein (CRP)) have accuracy below 85\% [14]. The newer inflammatory marker seems promising but has a higher cost and difficulty implementing primary or secondary medical care in developing countries. Therefore, there is a need for information on the difference in accuracy between the newer inflammatory marker and the routine, low-cost, complete blood count test. Our study aims to analyze the accuracy of WBC, NLR, PCT, D-Dimer, and CRP in predicting COVID-19 mortality. These findings may support the decision of clinical management protocols in developing countries. 


\section{Methods}

Study Design and Participants

This study was a retrospective cohort study of hospitalized patients with COVID-19 enrolled at Dr. Soetomo General Hospital (Surabaya City, East Java Province, Indonesia). All confirmed COVID-19 patients were screened, and those who had definite outcomes (death or discharged) between March 1st, 2020, and June 30th, 2020, were listed. From the total of 423 patients, then 28 pregnant patients, 8 patients with no RealTime Polymerase Chain Reaction (RT-PCR) test record, and 46 patients with no early laboratory tests were excluded, leaving 341 patients included in this study. Not all the patients received all parameters tests because of physicians' feasibility and clinical decision.

\section{Data Collection}

The age, length of hospitalization, and early laboratory test (WBC, neutrophil percentage, lymphocyte percentage, procalcitonin, D-Dimer, and CRP) were collected from secondary data from electronic medical records using a standardized data collection form. All data were checked twice to ensure the data retrieve correctly before being entered into a computerized database.

\section{Definitions}

The diagnosis of COVID-19 was defined according to the Indonesian Ministry of Health COVID-19 prevention and control guidelines (version 5.0) [15]. Detection of Severe Acute Respiratory Syndrome Coronavirus 2 (SARS-CoV-2) infection is done using real-time RT-PCR methods from nasopharyngeal swab specimens. The confirmative examination was conducted by the Diagnostic Center of Dr. Seotomo General Hospital, Surabaya. The criteria for discharge were complete isolation for ten days from the date of onset with a minimum of 3 days after an absence of fever and respiratory problems (for mild and moderate patients) or has obtained a negative one-time RT-PCR follow-up examination plus a minimum of 3 days after an absence of fever and respiratory problems (for severe and critical patients). The laboratory examination was conducted based on Dr. Soetomo General Hospital Clinical Practice Guidance. Neutrophil-Lymphocyte Ratio (NLR) was calculated by dividing the neutrophil percentage by the lymphocyte percentage.

\section{Statistical analysis}

The age, length of hospitalization, and laboratory data were presented as the median and interquartile range (IQR), while sex variables were presented as count (n) and percentage (\%). The Mann-Whitney $\mathrm{U}$ test and Chi-square test compared differences between the discharge and death groups. Survival analysis was performed using the Kaplan-Meier survival curve to measure survival probability during hospitalization, showing the Log Rank p-value. We use the Cox proportional hazard regression model to determine the hazard ratio (HR) during hospitalization. Receiver Operating Characteristic (ROC) curves were conducted to measure the Area Under the Curve (AUC) value, sensitivity, and specificity of a predictivevariable. All statistic was performed individually for each variable. Since the difference in the sample size of each laboratory data, we can not perform multivariable analysis to show the most influencing variables. We do Z-test between NLR to other laboratory parameters to compare the accuracy. Statistically significant was considered using two-sided $\alpha$ less than 0.05. Statistical analysis was done using the IBM SPSS software (version 13).

\section{Results}

Patients Characteristic and Comparative Test

The patient's baseline characteristics, early laboratory test, and comparative test results are presented in Table 1. A total of 423 patients who met the criteria for participating had a median age of 54 (IQR 45-61) years. Patients in the discharge group have lower age $(51.00$ vs. $55.00 ; P=0.000)$ and higher length of hospitalization (15.00 vs. $5.00 ; P=0.000)$ than patients in the death group. There is no significant difference in mortality between male and female patients $(P=0.514)$. The discharge group has significantly lower value than death group for WBC (7.71 vs $10.80 ; P=0.000$ ), NLR (4.43 vs $9.32 ; \mathrm{P}=0.000)$, PCT (0.13 vs $0.39 ; P=0.000)$, D-Dimer $(1010.00$ vs $2560.00 ; P$ $=0.000)$ and $\mathrm{CRP}(6.00$ vs $15.00 ; P=0.000)$ parameters.

Table 1. Baseline Characteristic and Early Laboratory Test of The Study Cohort

\begin{tabular}{|c|c|c|c|c|}
\hline Variables & Total $(n=341)$ & Discharge $(n=193)$ & Death $(n=148)$ & $p$-value \\
\hline Age (year) & $\begin{array}{l}54.00 \\
(45.00-61.00) \\
\end{array}$ & $\begin{array}{l}51.00 \\
(40.50-59.00) \\
\end{array}$ & $\begin{array}{l}55.00 \\
(47.25-65.00) \\
\end{array}$ & $0.000 * *$ \\
\hline Sex & & & & 0.514 \\
\hline Male & $189(55 \%)$ & $104(54 \%)$ & $85(57 \%)$ & \\
\hline Female & $152(45 \%)$ & $89(46 \%)$ & $63(43 \%)$ & \\
\hline Length of Hospitalization (days) & $\begin{array}{l}11.00 \\
(5.00-17.00)\end{array}$ & $\begin{array}{l}15.00 \\
(11.00-20.00)\end{array}$ & $\begin{array}{l}5.00 \\
(2.00-9.00) \\
\end{array}$ & $0.000^{* *}$ \\
\hline White Blood Cell Count $\left(10^{3} / \mathrm{uL}\right)(\mathrm{n}=325$ Patients) & $\begin{array}{l}8.73 \\
(6.42-12.06) \\
\end{array}$ & $\begin{array}{l}7.71 \\
(5.86-9.77) \\
\end{array}$ & $\begin{array}{l}10.80 \\
(7.88-15.02)\end{array}$ & $0.000 * *$ \\
\hline Neutrophil Lymphocyte Ratio (n=325 Patients) & $\begin{array}{l}6.02 \\
(3.48-10.64) \\
\end{array}$ & $\begin{array}{l}4.43 \\
(2.79-6-95) \\
\end{array}$ & $\begin{array}{l}9.32 \\
(5.81-15.12) \\
\end{array}$ & $0.000 * *$ \\
\hline Procalcitonin $(\mathrm{ng} / \mathrm{ml})(\mathrm{n}=249$ Patients $)$ & $\begin{array}{l}0.19 \\
(0.09-0.69)\end{array}$ & $\begin{array}{l}0.13 \\
(0.08-0.26) \\
\end{array}$ & $\begin{array}{l}0.39 \\
(0.16-1.71) \\
\end{array}$ & $0.000 * *$ \\
\hline D-Dimer (ng/ml) (n=184 Patients) & $\begin{array}{l}1390.00 \\
(712.50-5537.50)\end{array}$ & $\begin{array}{l}1010.00 \\
(520.00-2400.00)\end{array}$ & $\begin{array}{l}2560.00 \\
(1185.00-11395.00)\end{array}$ & $0.000^{* * *}$ \\
\hline C-Reactive Protein (mg/dL) (n=111 Patients) & $\begin{array}{l}9.70 \\
(3.80-15.90)\end{array}$ & $\begin{array}{l}6.00 \\
(1.50-11.90)\end{array}$ & $\begin{array}{l}15.00 \\
(9.78-19.45)\end{array}$ & $0.000 * *$ \\
\hline
\end{tabular}




\section{Survival Analysis}

As seen in Figure 1, by using old age criteria and prespecified cut-off (obtained from the diagnostic tools) for laboratory parameters, we compare the survival probability between discharge and death group using Kaplan-Meier Survival Curve. Patients with older age ( $>59$ years), higher WBC (>10.000/ul), $\mathrm{NLR}(>5)$, PCT $(>0.5 \mathrm{ng} / \mathrm{ml})$, d-dimer $(>440 \mathrm{ng} / \mathrm{ml})$, and CRP $(>1 \mathrm{mg} / \mathrm{dl})$ seem more vulnerable with lower survival during hospitalization. Patients older than 59 years have a significantly lower survival than patients younger than 59 years. Table 2 shows that all laboratory parameters predict patient mortality during hospitalization. Each addition of one year's age would increase 1.027 (95\% CI: 1.013-1.040; $P=0.000)$ times of mortality risk. The HR of other laboratory parameters are 1.041 (95\% CI: $1.025-1.057 ; P=0.000$ ) for WBC, 1.020 (95\% CI: 1.010-1.030; $P=0.000$ ) for NLR, 1.047 (95\% CI: 1.024-1.070; $P=0.000$ ) for PCT, 1.000 (95\% CI: $1.000-1.000 ; P=0.012$ ) for d-dimer, and 1.004 (95\% CI: 0.998-1.009; $P=0.209$ ).

Table 2. COX Regression Analysis of Predictive Variables

\begin{tabular}{|l|l|l|}
\hline Variables & HR $(95 \% \mathrm{CI})$ & $\mathrm{p}$-value \\
\hline Age (year) & $1.027(1.013-1.040)$ & $0.000^{* *}$ \\
\hline White Blood Cell Count (103/uL) (n= 325 Patients) & $1.041(1.025-1.057)$ & $0.000^{* *}$ \\
\hline Neutrophil Lymphocyte Ratio (n= 325 Patients) & $1.020(1.010-1.030)$ & $0.000^{* *}$ \\
\hline Procalcitonin (ng/ml) (n= 249 Patients) & $1.047(1.024-1.070)$ & $0.000^{* *}$ \\
\hline D-Dimer (ng/ml) (n= 184 Patients) & $1.000(1.000-1.000)$ & $0.012^{*}$ \\
\hline C-Reactive Protein (mg/dL) (n= 111 Patients) & $1.004(0.998-1.009)$ & 0.209 \\
\hline
\end{tabular}

HR $=$ Hazard Ratio $;$ p-value $<0.05 ; * *$ p-value $<0.01$

ROC Analysis and Comparison of AUC value

The AUC value of all variables is shown in Figure 2. Age has an AUC value of 0.633, a low accuracy category (0.6-0.7). The early laboratory parameter, WBC, NLR, procalcitonin, d-dimer, and CRP, have moderate accuracy (0.7-0.8). NLR accuracy is significantly greater than age in predicting patient mortality with a Z-test score of $3.527(\mathrm{p}=0.000)$. As shown in Table 3, we found a more excellent AUC value on NLR but no significant Z-test in other comparisons. As a result, NLR was comparable to other laboratory parameters in predicting COVID-19 patient mortality.

Table 3. Comparison of area under the curve of neutrophil-lymphocyte ratio to other parameters

\begin{tabular}{|c|c|c|c|c|}
\hline Variables & AUC of NLR & AUC of Comparator & Z-test & $p$-value \\
\hline NLR vs Age & \multirow{5}{*}{$\begin{array}{l}0.773 \\
(0.722-0.824)\end{array}$} & $0.633(0.574-0.692)$ & 3.527 & $0.000 * *$ \\
\hline NLR vs. WBC & & $0.709(0.652-0.767)$ & 1.643 & 0.100 \\
\hline NLR vs PCT & & $0.738(0.674-0.802)$ & 0.833 & 0.405 \\
\hline NLR vs D-Dimer & & $0.721(0.649-0.794)$ & 1.150 & 0.250 \\
\hline NLR vs CRP & & $0.769(0.679-0.858)$ & 0.076 & 0.939 \\
\hline
\end{tabular}

AUC $=$ Area Under the Curve CRP $=$ C-Reactive Protein $;$ NLR $=$ Neutrophil-Lymphocyte Ratio $;$ PCT $=$ Procalcitonin; WBC $=$ White Blood Cells; $* *$-value $<0.001$

\section{Discussion}

The increasing demand for managing COVID-19 cases has burdened medical healthcare systems. Implementing good triage by early identification of a patient's prognosis is essential to improve COVID-19 patient management. In this study, the high mortality percentage $(43.4 \%)$ might be caused by higher severe cases in Dr. Soetomo General Hospital due to its function as a national referral hospital. We found that all the variables involved in the patients' survival can be a predictor with low-moderate accuracy. We also found that NLR was comparable to other laboratory parameters in predicting COVID-19 patient mortality. Previous studies have reported the association between older age and COVID-19 mortality [1618]. We confirmed that patients with older age have lower survival during hospitalization. The decrease of immunity function due to immunosenescence may be involved in a patient's condition [19]. In addition, the elderly appears to develop sub-clinical chronic inflammation conditions, called inflame-aging, after viral or other pathogens infections [20]. The consequence of inflame-aging is deleterious effet to organ leading to a higher risk of mortality [21]. Consistent with other studies, our findings reported that patients with higher WBC count, NLR, PCT, D-Dimer, and CRP had higher odds of COVID-19 mortality [5,22,23]. Although several studies declare no significant result on the association of higher WBC with the severity, higher WBC may impact higher neutrophils cells which have a role in inflammation [23,24]. The higher NLR reflects the increase in pro-inflammatory cells and decreased lymphocytes and regulatory $\mathrm{T}$ cells, which have a role in controlling inflammation $[22,25]$. The use of PCT and CRP in COVID-19 patients may be based on their capability in detecting sepsis conditions [26,27]. The PCT showed high accuracy, while the CRP showed moderate accuracy in predicting sepsis [28]. Interestingly, these are also similar to the accuracy of both parameters in predicting COVID-19 severity, with the high accuracy for PCT and moderate accuracy for CRP [13]. D-dimer is also one of the standard parameters tested in COVID-19 patients. The significant association may be based on the potency of D-dimer to detect coagulopathy, the risk for venous thromboembolism, and excessive inflammation in COVID-19 infection [29]. The survival analysis shows the significance of all variables in determining the patient's mortality risk. 

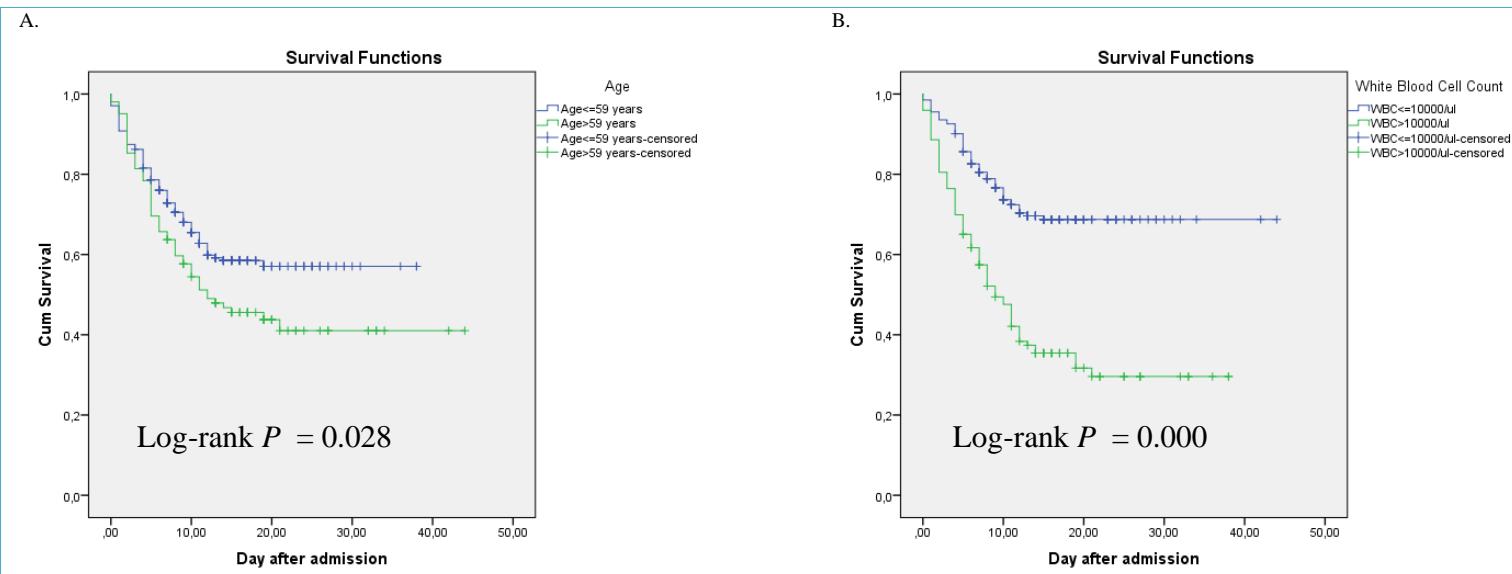

\section{Survival Functions}
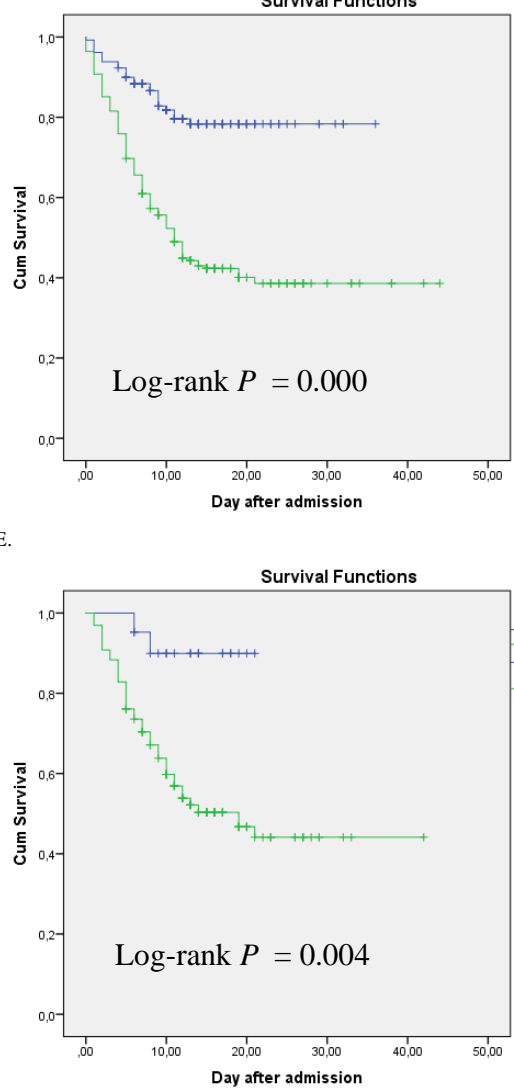
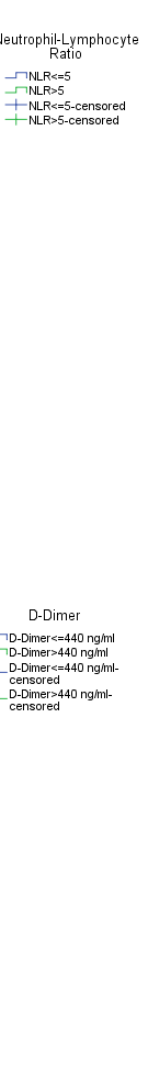
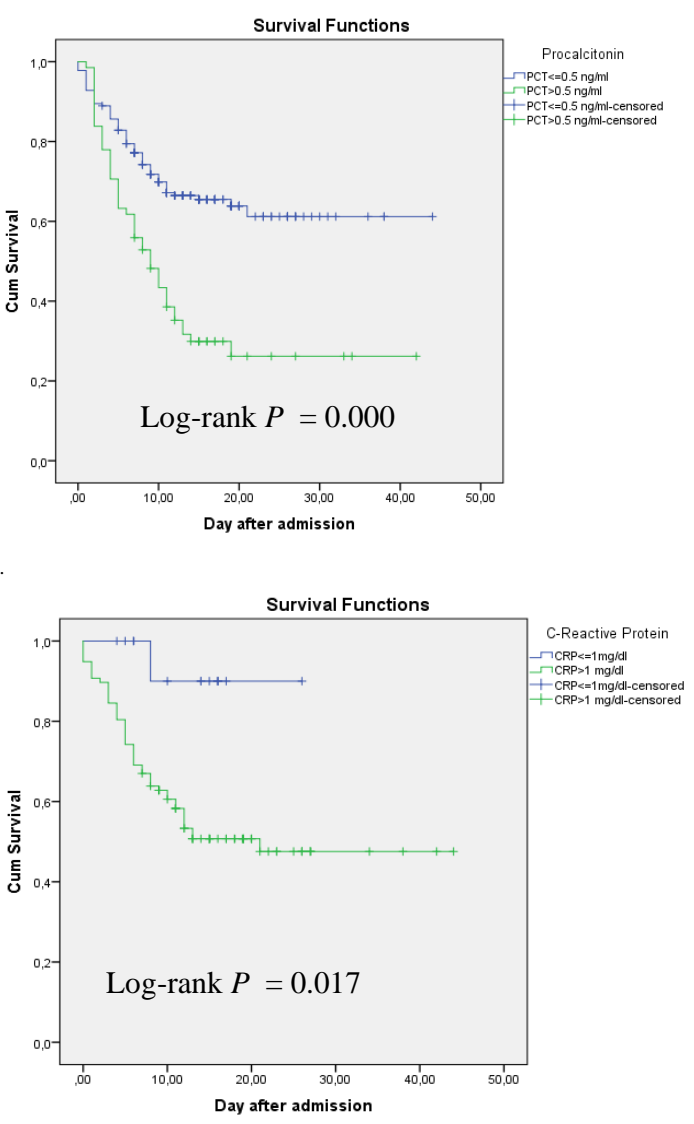

Figure 1. Kaplan-Meier Survival Curve of (A) Age (B) White Blood Cell Count (C) Neutrophil-Lymphocyte Ratio (D) Procalcitonin (E) D-Dimer (F) C-Reactive Protein for COVID-19 Patients Survival

This can be explained since all the variables are associated with inflammation [30]. Inflammation is responsible for the progression of tissue damage and organ injury, from mild to severe organ dysfunction leading to poor outcomes [31,32]. Sepsis and other organ dysfunction appear as complication and mortality cause in COVID-19 patients [33,34]. ROC curve analysis reveals low accuracy of age and moderate accuracy of all laboratory markers on predicting mortality of COVID-19 patients. The NLR has the highest accuracy with AUC 0.734 (95\% CI 0.675-0.793). This result is quite different from other studies reporting higher accuracy of PCT than other parameters [13], even though all the markers still show a significant accuracy to predict COVID-19 patient mortality. Z-test also showed no significant difference in accuracy between all laboratory markers, interpreted as all these markers have the same moderate accuracy in predicting COVID1-9 mortality. Hence, our study still recommends using conventional parameters, like WBC and NLR, for predicting the mortality of COVID-19, with better accessibility, feasibility, and affordable price, especially in developing countries. Until now, there are still few studies focused on analysis survival and predictive factors for COVID-19 mortality from developing countries in Southeast Asia. Our strength is to show the survival and predictive value of the conventional and "advanced" laboratory parameters. Therefore, our result can be used as a reference, especially for the developing countries which needed effective parameters with relatively low-cost expenditure. 


\section{Limitation of study}

Several limitations exist in our study. First, due to the limited sample tested by the "advanced" laboratory parameters, our accuracy comparison only can be conducted indirectly using the Z-test. Second, we cannot do the multivariate analysis due to the unequal sample size of each parameter. Finally, the investigators could not include other variables that may influence the result due to limited data on electronic medical records.

\section{Conclusion}

In conclusion, our study found a significant association between age and all laboratory markers (WBC, NLR, PCT, D-Dimer, and CRP) and COVID-19 patient mortality. All laboratory markers showed moderate accuracy as early predictors.
However, our study still suggests routine complete blood count tests as prognostic biomarkers with moderate accuracy and the highest feasibility to be performed in developing countries. Further research may look into comparing all these parameters with radiological markers or specific clinical conditions to improve the management of COVID-19, especially in developing countries.

\section{Abbreviation}

COVID-19: Coronavirus Disease 2019; WBC: White Blood Cells; NLR: Neutrophil-Lymphocyte Ratio; PCT: Procalcitonin; CRP: C-Reactive Protein; AUC: Area Under the Curve; RTPCR: Real-Time Polymerase Chain Reaction; SARS-CoV-2: Severe Acute Respiratory Syndrome Coronavirus 2; IQR: Interquartile Range; HR: Hazard Ratio

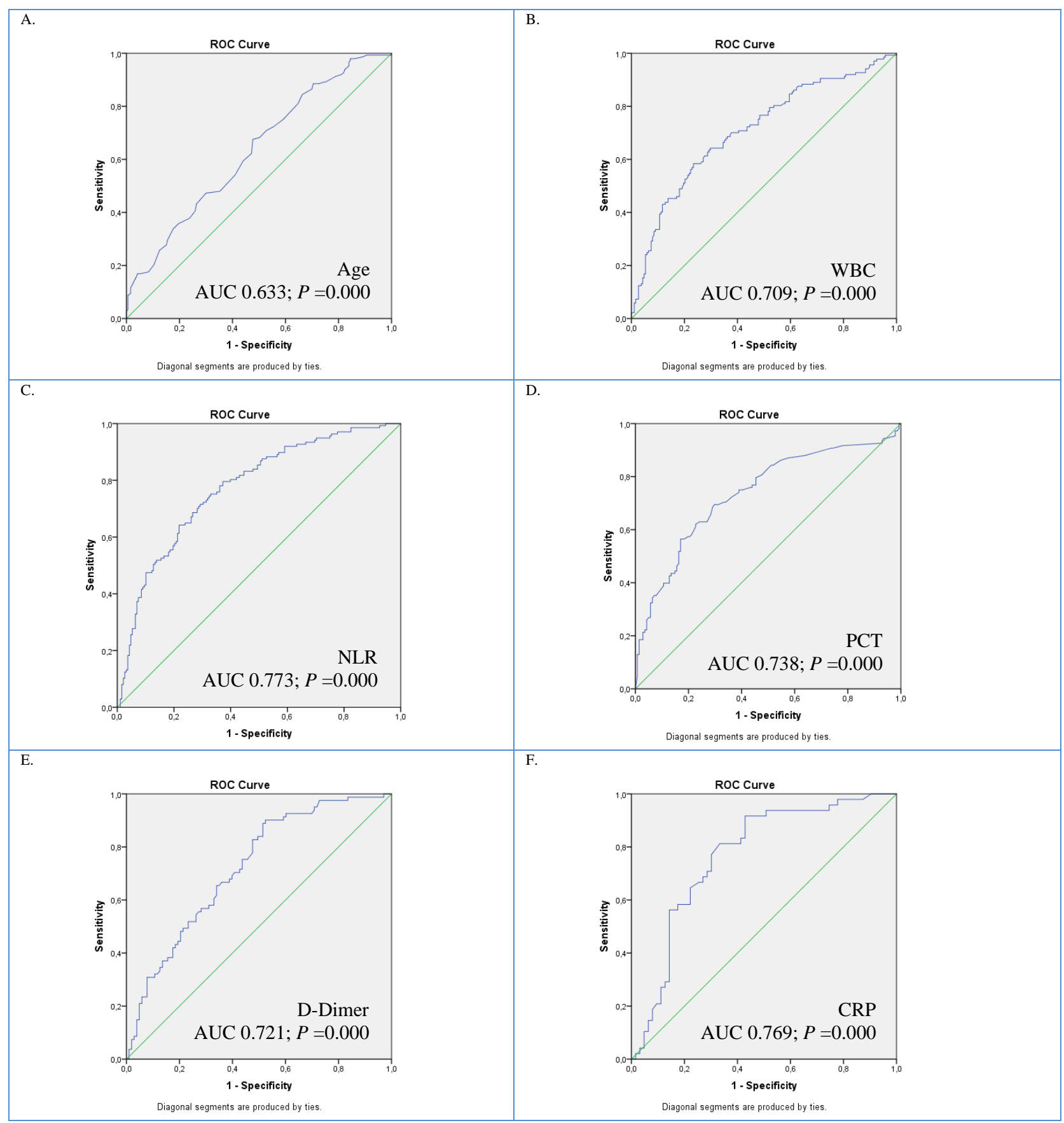

Figure 2. Receiver Operating Characteristic Curve of (A) Age (B) White Blood Cell Count (WBC) (C) Neutrophil-Lymphocyte Ratio (NLR) (D) Procalcitonin (PCT) (E) D-Dimer (F) C-Reactive Protein (CRP) for Prediction of COVID-19 Mortality 
Declaration

Acknowledgment

None.

Funding

The authors received no financial support for their research, authorship, and/or publication of this article.

Availability of data and materials

Data will be available by emailing

visuddho2018@fk.unair.ac.id

\section{Authors' contributions}

Visuddho Visuddho (VSD), Agus Subagjo (AGS), and Retno Asih Setyoningrum (RAS) are responsible for the study concept, design, data acquisition, and writing the original draft. VSD also performed the data analysis. Alfian Nur Rosyid (ANR) is responsible for editing and reviewing the manuscript. The approval of the final manuscript is done by all authors.

Ethics approval and consent to participate

We conducted the research following the Declaration of Helsinki. The ethical protocol was approved by the Research Ethics Commission of Dr. Soetomo General Hospital (Ref. No: 0257/LOE/301.4.2/XII/2020).

\section{Consent for publication}

Not applicable

Competing interest

The authors declare that they have no competing interests.

\section{Open Access}

This article is distributed under the terms of the Creative Commons Attribution 4.0 International License (http://creativecommons.org/licenses/by/4.0/), which permits unrestricted use, distribution, and reproduction in any medium, provided you give appropriate credit to the original author(s) and the source, provide a link to the Creative Commons license, and indicate if changes were made. The Creative Commons Public Domain Dedication waiver (http://creativecommons.org/publicdomain/zero/1.0/) applies to the data made available in this article unless otherwise stated.

\section{Author Details}

${ }^{1}$ Medical Programme, Faculty of Medicine, Universitas Airlangga, Surabaya, Indonesia.

${ }^{2}$ Department of Cardiology and Vascular Medicine, Faculty of Medicine, Universitas Airlangga, Surabaya, Indonesia.

${ }^{3}$ Department of Pediatrics, Faculty of Medicine, Universitas Airlangga, Surabaya, Indonesia.

${ }^{4}$ Department of Pulmonology and Respiratory Medicine, Faculty of Medicine, Universitas Airlangga, Surabaya, Indonesia.

\section{Article Info}

Received: 13 December 2021

Accepted: 29 December 2021

Published: 31 December 2021
References

1. World Health Organization. COVID-19 Weekly Epidemiological Update July 27th, 2021 [Internet]. World Health Organization. 2021. https://www.who.int/docs/defaultsource/coronaviruse/situationreports/weekly_epidemiological_update_22.pdf

2. World Health Organization. Coronavirus Disease 2019 (COVID-19) Situation Report - 66 [Internet]. 2021. https://cdn.who.int/media/docs/defaultsource/searo/indonesia/covid19/external_situation_report_ 66_4_august_2021_final.pdf?sfvrsn=ad645ea_5

3. Liang W, Liang H, Ou L, Chen B, Chen A, Li C, et al. Development and validation of a clinical risk score to predict the occurrence of critical illness in hospitalized patients with COVID-19. JAMA Intern Med. 2020;180(8):1081-9. https://doi.org/10.1001/jamainternmed.2020.2033

4. Hu H, Du H, Li J, Wang Y, Wu X, Wang C, et al. Early prediction and identification for severe patients during the pandemic of COVID-19: A severe COVID-19 risk model constructed by multivariate logistic regression analysis. J Glob Health. 2020;10(2):1-12. https://doi.org/10.7189/jogh.10.020510

5. Henry BM, de Oliveira MHS, Benoit S, Plebania M, Lippi G. Hematologic, biochemical and immune biomarker abnormalities associated with severe illness and mortality in coronavirus disease 2019 (COVID-19): a meta-analysis. Clin Chem Lab Med. 2020;58(7):1021-1028.

6. Ji P, Zhu J, Zhong Z, Li H, Pang J, Li B, et al. Association of elevated inflammatory markers and severe COVID-19: A meta-analysis. Medicine (Baltimore). 2020;99(47):e23315. https://doi.org/10.1097/MD.0000000000023315

7. Pourbagheri-sigaroodi A, Bashasha D, Fatehb F, Abolghasemi H. Laboratory findings in COVID-19 diagnosis and prognosis. Clin Chim Acta. 2020;510(2020):475-482. https://doi.org/10.1016/j.cca.2020.08.019

8. Ponti G, Maccaferri M, Ruini C, Tomasi A, Ozben T. Biomarkers associated with COVID-19 disease progression. Crit Rev Clin Lab Sci. 2020;0(0):389-99. https://doi.org/10.1080/10408363.2020.1770685

9. Anurag A, Jha PK, Kumar A. Differential white blood cell count in the COVID-19: A cross-sectional study of 148 patients. Diabetes Metab Syndr Clin Res Rev. 2020;14(January):2099-102. https://doi.org/10.1016/j.dsx.2020.10.029

10. Seyit M, Avci E, Nar R, Senol H, Yilmaz A, Ozen M, et al. Neutrophil to lymphocyte ratio, lymphocyte to monocyte ratio and platelet to lymphocyte ratio to predict the severity of COVID- 19. Am J Emerg Med. 2020;40(2021):110-114. https://doi.org/10.1016/j.ajem.2020.11.058

11. Elshazli RM, Toraih EA, Elgaml A, El-Mowafy M, ElMesery M, Amin MN, et al. Diagnostic and prognostic value of hematological and immunological markers in COVID-19 infection: A meta-analysis of 6320 patients. PLoS One. 2020;15(8):e0238160. http://dx.doi.org/10.1371/journal.pone.0238160

12. Yang A, Liu J, Tao W, Li H. The diagnostic and predictive role of NLR, d-NLR and PLR in COVID-19 patients. Int Immunopharmacol. $2020 ; 84$. https://doi.org/10.1016/j.intimp.2020.106504 
13. Zare ME, Wang Y, Kansestani AN, Almasi A, Zhang J. Procalcitonin has good accuracy for prognosis of critical condition and mortality in COVID-19: A diagnostic test accuracy systematic review and meta-analysis. Iran $\mathbf{J}$ Allergy, Asthma Immunol. 2020;19(6):557-69. https://doi.org/10.18502/ijaai.v19i6.4926

14. Sayah W, Berkane I, Guermache I, Sabri M, Lakhal FZ, Yasmine Rahali S, et al. Interleukin-6, procalcitonin and neutrophil-to-lymphocyte ratio: Potential immuneinflammatory parameters to identify severe and fatal forms of COVID-19. Cytokine. 2021;141(2021):155428 Contents. https://doi.org/10.1016/j.cyto.2021.155428

15. Keputusan Menteri Kesehatan Republik Indonesia. Keputusan Menteri Kesehatan Republik Indonesia Nomor HK.01.07/MenKes/413/2020 Tentang Pedoman Pencegahan dan Pengendalian Corona Virus Disease 2019 (Covid-19). MenKes/413/2020. 2020;2019:207.

16. Atkins JL, Masoli JAH, Delgado J, Pilling LC, Kuo CL, Kuchel GA, et al. Preexisting Comorbidities Predicting COVID-19 and Mortality in the UK Biobank Community Cohort. Journals Gerontol - Ser A Biol Sci Med Sci. 2020;75(11):2224-30. https://doi.org/10.1093/gerona/glaa183

17. Chen Y, Klein SL, Garibaldi BT, Li H, Wu C, Osevala NM, et al. Aging in COVID-19: Vulnerability, immunity and intervention. Ageing Res Rev. 2021;65:101205. https://doi.org/10.1016/j.arr.2020.101205

18. Perrotta F, Corbi G, Mazzeo G, Boccia M, Aronne L, D'Agnano V, et al. COVID-19 and the elderly: insights into pathogenesis and clinical decision-making. Aging Clin Exp Res. 2020;32(8):1599-608. https://doi.org/10.1007/s40520-020-01631-y

19. Kadambari S, Klenerman P, Pollard AJ. Why the elderly appear to be more severely affected by COVID-19: The potential role of immunosenescence and CMV. Rev Med Virol. 2020;30(5):1-5. https://doi.org/10.1002/rmv.2144

20. Pietrobon AJ, Teixeira FME, Sato MN. I mmunosenescence and Inflammaging: Risk Factors of Severe COVID-19 in Older People. Front Immunol. 2020;11:1-18. https://doi.org/10.3389/fimmu.2020.579220

21. Omarjee L, Perrot F, Meilhac O, Mahe G, Bousquet G, Janin A. Immunometabolism at the cornerstone of inflammaging, immunosenescence, and autoimmunity in COVID-19. Aging (Albany NY). 2020;12(24):26263-78. https://doi.org/10.18632/aging.202422

22. Liu Y, Du X, Chen J, Jin Y, Peng L, Wang HHX, et al. Neutrophil-to-lymphocyte ratio as an independent risk factor for mortality in hospitalized patients with COVID19. J Infect. 2020;81(1):e6-12. https://doi.org/10.1016/j.jinf.2020.04.002

23. Moradi EV, Teimouri A, Rezaee R, Morovatdar N, Foroughiana M, Layegh $\mathrm{P}$, et al. Increased age, neutrophil- to-lymphocyte ratio (NLR) and white blood cells count are associated with higher COVID-19 mortality. Am J Emerg Med. 2020;40(2021):11-14. https://doi.org/10.1016/j.ajem.2020.12.003

24. Marik PE, Stephenson E. The ability of Procalcitonin, lactate, white blood cell count and neutrophil-lymphocyte count ratio to predict blood stream infection. Analysis of a large database. J Crit Care. 2020;60:135-9. https://doi.org/10.1016/j.jcrc.2020.07.026

25. Qin C, Zhou L, Hu Z, Zhang S, Yang S, Tao Y, et al. Dysregulation of Immune Response in Patients with COVID-19 in Wuhan, China. SSRN Electron J. 2020; https://doi.org/10.2139/ssrn.3541136

26. Cui N, Zhang H, Chen Z, Yu Z. Prognostic significance of PCT and CRP evaluation for adult ICU patients with sepsis and septic shock: retrospective analysis of 59 cases. J Int Med Res. 2019;47(4):1573-9. https://doi.org/10.1177/0300060518822404

27. Mierzchała-Pasierb M, Lipinska-Gediga M. Sepsis diagnosis and monitoring - Procalcitonin as standard, but what next? Anaesthesiol Intensive Ther. 2019;51(4):299305. https://doi.org/10.5114/ait.2019.88104

28. Tan M, Lu Y, Jiang H, Zhang L. The diagnostic accuracy of procalcitonin and $\mathrm{C}$-reactive protein for sepsis: A systematic review and meta-analysis. J Cell Biochem. 2019;120(4):5852-9. https://doi.org/10.1002/jcb.27870

29. Rostami M, Mansouritorghabeh H. D-dimer level in COVID-19 infection: a systematic review. Expert Rev Hematol. 2020;13(11):1265-75. https://doi.org/10.1080/17474086.2020.1831383

30. Zeng F, Huang Y, Guoa Y, Yina M, Chena X, Xiao L, et al. Association of inflammatory markers with the severity of COVID-19: A meta-analysis. Int $\mathrm{J}$ Infect Dis. 2020;96(2020):467-474. https://doi.org/10.1016/j.ijid.2020.05.055

31. Mortaz E, Alipoor SD, Adcock IM, Mumby S, Koenderman L. Update on neutrophil function in severe inflammation. Front Immunol. 2018;9:1-14. https://doi.org/10.3389/fimmu.2018.02171

32. Sauaia A, Moore F, Moore E. Postinjury Inflammation and Organ Dysfunction. Crit Care Clin. 2017;33(1):167-91. https://doi.org/10.1016/j.ccc.2016.08.006

33. Devaux C, Rolain J, Raoult D. ACE2 receptor polymorphism: Susceptibility to SARS-CoV-2, hypertension, multi-organ failure, and COVID-19 disease outcome. J Microbiol Immunol Infect. 2020;53(3):425-35. https://doi.org/10.1016/j.jmii.2020.04.015

34. Zhou F, Yu T, Du R, Fan G, Liu Y, Liu Z, et al. Clinical course and risk factors for mortality of adult in patients with COVID-19 In Wuhan, China: A Retrospective Cohort Study. Lancet. 2020;395:1054-62. https://doi.org/10.24966/msr-5657/100015. 